\title{
Ações educativas em um Programa de Agentes Comunitários de Saúde
}

\author{
Educational actions in a Community Healthcare Agents Program \\ Acciones educativas en un Programa de Agentes Comunitarios de Salud
}

\section{Patricia Fidali Bonfim', Cinira Magali Fortuna", Carmen Silvia Gabriel'", Maria Cristina Durante ${ }^{\mathrm{IV}}$}

'Colégio 24 de Março, Curso de Auxiliar Técnico em Enfermagem. São Paulo-SP, Brasil.

"Universidade de São Paulo, Escola de Enfermagem de Ribeirão Preto,

Departamento Materno Infantil e Saúde Pública. Ribeirão Preto-SP, Brasil.

I"' Universidade de São Paulo, Escola de Enfermagem de Ribeirão Preto,

Departamento de Enfermagem Geral e Especializada. Ribeirão Preto-SP, Brasil.

IV Universidade de Ribeirão Preto, Curso de Medicina, Curso de Enfermagem. Ribeirão Preto-SP, Brasil.

\author{
Submissão: 16-10-2010Ａprovação: 19-07-2012
}

\begin{abstract}
RESUMO
Este estudo teve por objetivo identificar e analisar as ações educativas realizadas por um Programa de Agentes Comunitários de Saúde de uma cidade do interior do estado de São Paulo, considerando as concepções pedagógicas e os aspectos intervenientes que aproximam e afastam a equipe da mudança de prática pretendida pelo programa. É uma pesquisa de abordagem qualitativa do tipo estudo de caso. Foram realizadas entrevistas semiestruturadas com análise de conteúdo, modalidade temática. O estudo evidenciou que a concepção pedagógica predominante é a da transmissão de informações voltada para prevenção de doenças, embora existam algumas ações próximas da pedagogia participativa. A organização do trabalho e o vínculo com a população também interferem no trabalho educativo. Conclui-se que as ações educativas ainda são alicerçadas no preventivismo com desafios para promoção da saúde e carecem de investimentos em formação e na organização da rede assistencial.

Descritores: Educação em Saúde; Atenção Primária á Saúde; Serviços de Saúde; Enfermagem.
\end{abstract}

\begin{abstract}
This study aimed to identify and analyze the actions performed by an educational program of Community Health Agents of a city in the state of Sao Paulo, Brazil, considering the educational concepts, the team approach and aspects which influence in desired change by the program. It is a qualitative research using case study. Semi-structured interviews were conducted that were treated with content analysis, thematic modality. The study showed that the predominant pedagogical concept is the transmission of information aimed at disease prevention, although there are some actions near the participative pedagogy. The organization of work and the link with the population also influence the educational work. It is concluded that educational activities are still grounded in Preventive challenges for health promotion and lack of investment in training and organization of health care network. Key words: Health Education, Primary Health Care, Health Services, Nursing.
\end{abstract}

\section{RESUMEN}

Este estudio tuve por objetivo identificar y analizar las acciones educativas realizadas por un Programa de Agentes Comunitarios de Salud de una ciudad del estado de São Paulo, considerando las concepciones pedagógicas que las nortean y los aspectos intervinientes que aproximan y apartan el equipo del cambio pretendido. Esta investigación cualitativa del tipo estudio de caso utilizó entrevista semi estructurada y análisis temático. El estudio evidencio que la concepción pedagógica predominante es la de la transmisión de informaciones dirigidas a la prevención de enfermedades, aunque existan algunas acciones próximas de la pedagogía participativa. La organización del trabajo y el vínculo con la población también interfieren en el trabajo educativo. Las acciones educativas todavía son basadas en la prevención, con desafíos para la promoción de la salud y hay carencia de inversión en formación y organización de la red de atención de salud.

Palabras clave: Educación en salud; Atención Primaria de Salud; Servicios de Salud; Enfermería. 


\section{INTRODUÇÃO}

O Ministério da Saúde, desde 1997, reconhece o Programa de Agentes Comunitários de Saúde (PACS) como uma importante estratégia no aprimoramento e na consolidação da atenção básica à saúde no Sistema Único de Saúde (SUS) ${ }^{(1)}$.

Tanto o PACS como o Estratégia Saúde da Família (ESF) são formas de organizar a Atenção Básica e têm por finalidade a mudança do modelo assistencial em curso, que se caracteriza por ser um modo de organizar serviços e produzir ações de saúde centrado em procedimentos, fragmentado, biologicista e medicalizante. $\mathrm{O}$ modelo de atenção almejado é aquele que se norteia pelo cuidado integral, pela resolutividade, pela garantia do direito à saúde, desenvolvido através de práticas participativas e democráticas, contribuindo para a construção da autonomia dos sujeitos envolvidos ${ }^{(2)}$.

As atividades do PACS pautam-se no trabalho em equipe, sendo esta composta por agentes comunitários de saúde e enfermeira, vinculados a uma Unidade Básica de Saúde (UBS). A equipe deve orientar-se pelo diagnóstico das necessidades de saúde de um dado território, visando construir a integralidade da assistência através de ações de promoção, prevenção, reabilitação e cura.

Uma das ações que se espera no PACS é a realização de atividades de educação em saúde. Essa é uma ferramenta de trabalho que muitas vezes é compreendida como passagem ou transferência de informações sobre algum assunto com vistas a gerar adoção de hábitos saudáveis, adesão ao tratamento, prevenção e redução de danos, dentre outras ${ }^{(3)}$.

No entanto, na direção da mudança de modelo assistencial pretendida, a educação em saúde necessita de ampliações da ordem da práxis para que seja capaz de abrir diálogos entre os saberes dos usuários e dos trabalhadores na perspectiva da produção de novos sentidos e significados para os modos de viver e de se cuidar em saúde ${ }^{(3-4)}$.

A educação em saúde nessa direção precisa lançar mão de estratégias de ensino-aprendizagem ativas que possibilitem a apreensão critica da realidade vivenciada e da produção do adoecimento em dadas condições de vida(5).

As pesquisas a respeito do trabalho desenvolvido na atenção básica e em especial sobre educação em saúde e sobre o agente comunitário de saúde apontam para as deficiências quanto a formação dos trabalhadores de saúde, dificuldades no trabalho desenvolvido pelas equipes e ausência de avaliação sistemática do impacto dessas dificuldades nos indicadores de saúde ${ }^{(3)}$.

O modo como a equipe conceitua a educação em saúde e coloca em prática essas ações pode aproximá-la ou distanciá-la da construção de um novo modo de atender e produzir saúde. Dessa forma, essa pesquisa lança olhares sobre as ações educativas desenvolvidas por uma equipe de PACS, sob a ótica desses trabalhadores. As questões que nortearam a investigação foram as seguintes: Quais ações os trabalhadores do PACS consideram como educativas? Quais concepções pedagógicas norteiam essas ações? Essas ações aproximam a equipe de seu intento de mudar as práticas? Assim, este estudo tem por objetivo identificar e analisar as ações educativas, realizadas por um Programa de Agentes Comunitário de
Saúde de uma cidade do interior do estado de São Paulo, considerando as concepções pedagógicas que as norteiam, assim como os aspectos intervenientes que aproximam e afastam a equipe da mudança assistencial pretendida.

\section{PERCURSO METODOLÓGICO}

Trata-se de pesquisa de abordagem qualitativa, do tipo estudo de caso $^{(7)}$, em que se procurou conhecer e analisar as ações educativas realizadas, compreendendo as concepções dessas ações para os trabalhadores que as executam.

A unidade PACS estudada localiza-se no interior do estado de São Paulo, em um município de pequeno porte, com população estimada de 36.593 habitantes ${ }^{(8)}$. O principal setor de trabalho da população relaciona-se com atividades na indústria sucroalcooleira, o que dá origem a características específicas ao município, pois parte de sua população é transitória, vinda para o trabalho na safra da cana-de-açúcar, e alguns desses imigrantes retornam a suas cidades de origem após o término do trabalho, enquanto outros se fixam na cidade, trazendo outros familiares, com seus valores e costumes.

O município conta em sua rede assistencial com uma unidade Saúde da Família e uma UBS com PACS, além de um centro de saúde, um hospital Santa Casa e uma Unidade de Saúde Mental. A unidade PACS, na época da coleta de dados, atendia 354 famílias com um total de 1.200 pessoas, cujo diagnóstico da área revelava como principais problemas de saúde a hipertensão arterial, diabetes, depressão, problemas respiratórios e cardíacos, além de alcoolismo e uso de drogas.

Os sujeitos da pesquisa foram sete dos oito trabalhadores da única equipe de PACS do município, constituída por cinco agentes comunitários, uma técnica de enfermagem e uma enfermeira. $\mathrm{O}$ critério de inclusão dos sujeitos foi pertencer à equipe de PACS, estar em atividade no período de coleta de dados e a anuência em participar do estudo. Houve a exclusão de uma agente comunitária que na ocasião da coleta de dados estava em férias.

Foram realizadas entrevistas semiestruturadas, gravadas e posteriormente transcritas para análise. As entrevistas continham identificação dos trabalhadores, que foram perguntados sobre a idade, a escolaridade, o tempo de trabalho no PACS, formação para o trabalho no PACS e se teve ou não algum preparo para o desenvolvimento das ações educativas. Após essa identificação inicial passávamos para as questões específicas: Para você, o que são ações educativas? Quais atividades educativas são desenvolvidas pelo PACS? Quem planeja as ações educativas e como são preparadas e executadas? Dê-me um exemplo de ação educativa que considera ter sido exitosa, e por quê. Dê-me um exemplo de ação educativa que considera não exitosa, e por quê.

O projeto de pesquisa seguiu as recomendações da Comissão Nacional de Ética em Pesquisa com seres humanos, sendo aprovado sob o número 087/07. Inicialmente o projeto de pesquisa foi apresentado para a equipe, seguido de conversa individual na qual os trabalhadores foram consultados sobre o interesse em participar, tendo assinado o termo de consentimento livre esclarecimento. 
Os sujeitos da pesquisa foram tratados no anonimato, não sendo identificados nem expostos, reconhecidos a partir de nomes de pássaros. Para a análise do material empírico obtido nas entrevistas utilizou-se análise temática ${ }^{(7)}$ composta das seguintes ações: as transcrições foram impressas em duas vias e lidas exaustivamente, seguida da identificação de núcleos de sentido e de categorias temáticas. Foram utilizadas referências bibliográficas que pudessem auxiliar a confrontação teórica com os achados.

\section{RESULTADOS E DISCUSSÃO}

Em relação à faixa etária e sexo constatou-se que todos os sujeitos da pesquisa eram do sexo feminino e tinham idade entre 25 e 35 anos. Quanto ao grau de instrução, quatro agentes possuem ensino médio completo e uma, ensino fundamental completo, todas as ACS e a técnica de enfermagem já fizeram algum curso sobre ação educativa.

Em relação à formação específica em saúde da família, todas as ACS cursaram o primeiro módulo do curso técnico para ACS, a enfermeira não possui especialização em saúde da família e a técnica de enfermagem não participou de nenhuma formação específica para a atenção básica.

A formação da equipe de atenção básica e em especial da Estratégia Saúde da Família ainda requer especialmente efetiva mudança das práticas e do modelo assistencial ${ }^{(9)}$. Nota-se que a formação se faz por categorias profissionais e muitas vezes por iniciativa própria dos trabalhadores.

$\mathrm{Na}$ análise das entrevistas identificamos núcleos de sentido que foram agrupados em dois grandes temas. O primeiro, denominado "Concepções que sustentam as práticas educativas", engloba os núcleos de sentido: Educar é transmitir; Educação em saúde como prevenção de doenças; Ação educativa e promoção de saúde. O segundo tema, denominado "A organização do trabalho", aborda os núcleos de sentido: Apoio da gestão para educação em saúde; A educação em saúde se faz com toda a equipe; $\mathrm{O}$ ato educativo envolve acolhimento e escuta: tudo que a gente faz é educativo.

\section{CONCEPÇÕES QUE SUSTENTAM AS PRÁTICAS EDUCATIVAS}

Apresentaremos a seguir as concepções dos trabalhadores entrevistados acerca das práticas educativas.

\section{Educar é transmitir}

A concepção pedagógica da equipe aproxima-se da perspectiva da transmissão de informações; quanto a esse aspecto não encontramos diferenças significativas nas falas das agentes comunitárias, técnica de enfermagem e enfermeira.

Ação educativa no meu trabalho mesmo, pra estar fazendo com a comunidade a gente passa informações, né. Para pessoas nas visitas sobre educação, sobre saúde, sobre comportamento, né. Os adolescentes também. (...) Aí a gente vai atrás e estuda, eles gostam de saber o que eles têm: hipertensão, diabetes; aí a gente leva as respostas para eles (Bem-te-vi).
As visitas domiciliares de casa em casa levando informações de várias coisas; assim: a gente tem a caminhada, ensina a elas a estar caminhando, a importância do exercício físico, que é bom pra saúde, tudo isso... (Andorinha).

A pedagogia da transmissão considera o educando como uma folha em branco cujo principal objetivo é receber e o do educador é passar conhecimento ${ }^{(10)}$.

Essa proposta é ainda hegemônica no que se refere à educação; assim, é de esperar que apareça com força nas falas dos sujeitos desta pesquisa. Perspectiva semelhante foi também apresentada por outros estudiosos do tema ${ }^{(3-5,11)}$.

Um dos problemas do uso muito frequente dessa concepção pedagógica é que seus participantes podem fazer da informação o principal aspecto do processo educativo. Há um agente que passa a informação e outros que a recebem de modo passivo ${ }^{(10)}$. Essa passividade faz com que haja uma "entrega" de conhecimento sem se problematizar a ação. Incorpora-se a informação sem mudar atitudes e valores. Outra ação relatada pelos trabalhadores são as palestras.

Também a gente está sempre promovendo palestras sobre hipertensão e diabetes, cursinho com as gestantes; sabe, tem bastante coisa, a gente está sempre promovendo alguma coisa (Sabiá).

A literatura aponta que palestras e orientações individuais comumente transmitem a ideia de que cada doença se deve principalmente à falta de cuidado e ao desleixo da população ${ }^{(6,11-12)}$. Esse argumento é usado numa tentativa de criar um sentimento de culpa nas pessoas para que elas se esforcem para seguir as orientações dadas ${ }^{(12)}$.

Caso seja essa a direção das ações educativas, estabelece-se um aspecto limitante para se produzirem ações de saúde na direção da mudança do modelo assistencial, pois a perspectiva bancária da educação não corresponde à intenção de produzir sujeitos ativos, cidadãos capazes de mudar a própria realidade em que vivem ${ }^{(13-15)}$.

$\mathrm{Na}$ reprodução da concepção bancária, percebe-se que as possibilidades de se pensar a participação dos sujeitos envolvidos no processo educativo estão reduzidas, partindo da questão de que o participar, quando se investe de todo seu significado, implica ter parte nas decisões, e não apenas ser informado ou mesmo receber alguma coisa.

Outro aspecto relacionado à concepção bancária de ensino e aprendizagem é a permanência de relações verticalizadas de poder, pois as palestras e orientações domiciliares muitas vezes são passagens pontuais e generalizadas de informações sob a ótica e referencial da saúde.

Isso contribui para a pouca troca de saberes e compreensão dos valores que perpassam o processo saúde/doença e as relações sociais implicadas, prevalecendo a ideia de que o trabalhador sabe e passa, e o usuário recebe e faz sua parte.

...tem que ter profissionais, né, para estarem explicando; também tem que ter colaboração deles, também colaboração do usuário com quem está passando (Gaivota). 
Essa fala expressa uma expectativa que pode comandar os processos educativos: a de que o outro colabore; leia-se o colabore como adesão às orientações e às medidas prescritivas. Como essas medidas muitas vezes não consideram os valores culturais, a realidade vivenciada e a forma de pensar dos envolvidos, essa expectativa não se cumpre, desmotivando os trabalhadores. Acredita-se que a formação escolar e profissional desses agentes se deu nessa mesma perspectiva, mas os dados levantados não nos permitem fazer tal afirmação.

Dificuldade eu acho da população aderir, fazer o que realmente a gente está pedindo (Gaivota).

Às vezes tem algumas ações que não foram para frente, sabe, igual com a gestante adolescente: é muito difícil a gente conseguir trazer elas ainda para cá, tudo o que a gente tenta fazer... o começo até vai mais, aí no meio para. Fizemos enxoval, fizemos café da manhã; é assim, começa, mas não termina (Beija-flor).

Podemos perceber que às vezes a ação educativa não considera a experiência do usuário com relação ao assunto. Reconhecer o saber que vem a partir da experiência pode ser amenizador das frustrações dos trabalhadores e ponto de partida para a ação educativa.

Já a gente não chega à conclusão porque de tudo nós já tentamos fazer; agora elas falam que já sabem, às vezes já é o segundo filho, já é experiente, já sabe de tudo (Kalopsita).

Iniciar o diálogo a partir do que a população sabe pode ser um modo de construir a ação educativa com ela, e não para ela; assim, interesse e participação poderiam ser efetivos ${ }^{(9,13)}$.

A reflexão da equipe sobre como se aprende e sobre as concepções pedagógicas pode ser uma possibilidade de reorientação das ações educativas.

Como possível brecha de rompimento com a concepção bancária está a constatação dos trabalhadores de que, se não houver consideração da realidade vivenciada e se não houver acolhimento e escuta, as ações educativas estarão fadadas ao insucesso.

Ao comentar uma ação educativa que não teve êxito, uma trabalhadora relatou o seguinte:

...fomos dar palestra lá na escola; não virou uma palestra, virou risos, piadinhas. Era a quinta série e misturou menino com menina. Não!!! Virou foi uma bagunça, não obedeceram a professora, ficamos falando e as alunas eram novas; então achei que não teve comunicação. Acho que tem que trabaIhar assim: menino separado da menina, tem que separar e tem que virar um papo, não palestra, uma roda para conversa, bater papo (...). Mas essa ação acho que não valeu a pena! Daquela forma, não! Eu achei que esse foi frustrado (Canário).

A experiência com uma ação educativa na escola em forma de palestra e que não foi bem-sucedida abre para a possibilidade de se investir no diálogo, nas rodas de conversa, o que estaria mais adequado na perspectiva do desenvolvimento da autonomia e da troca de saberes necessários para mudanças nas práticas de saúde. Outra trabalhadora relatou o seguinte:

...o grupo de que eu também fazia parte que era o grupo de educação alimentar, que não deu certo porque, da forma que foi elaborado com a coordenadora, ela afastou as pessoas, isso não, de jeito nenhum! As pessoas não gostaram e não vieram mais: não vou mais porque eu não vou parar de comer isso, porque só tenho isso! Não! e então, foi bem negativo (Bem-te-vi).

Destacamos aqui a resposta da população, que, ao não participar da ação proposta, realiza uma resistência às práticas de dominação e de desconsideração de sua realidade e de seus saberes. Essa resistência muitas vezes é tida como negativa por trabalhadores de saúde, sendo categorizada como baixa adesão, mas revela a sabedoria das pessoas e suas estratégias de sobrevivência ${ }^{(14-15)}$.

\section{Ação educativa como prevenção de doenças}

Os trabalhadores relacionaram a educação em saúde às medidas de prevenção das doenças. Parece que esperam evitar os riscos através da passagem das informações:

...eu considero que tudo que é voltado à prevenção educa a população, tanto a criança como o idoso (Bem-te-vi).

No Brasil, houve períodos de maior ênfase à prevenção ou à cura das doenças. Essas perspectivas sempre estiveram atreladas aos interesses econômicos e políticos.

A divisão entre prevenção e cura como momentos separados e opostos distancia-se da atual perspectiva da integralidade, que é um dos princípios e diretrizes do SUS: a integralidade pressupõe a atenção ao indivíduo, à família e à comunidade (inserção social), e não um recorte de ações ou enfermidades; a integralidade implica em uma recusa do reducionismo, recusa à objetivação dos sujeitos e uma abertura para o diálogo ${ }^{(15)}$. O cuidado integral pode significar a realização de ações de promoção, prevenção, cura e reabilitação em estreita articulação.

A noção de prevenção de doenças está mais vinculada a uma visão biologicista e comportamentalista do processo saúde-doença. Ela se volta à identificação de riscos, atua sobre eles, mas não considera de sua alçada a gênese desses riscos, nem o estudo de suas naturezas, mecanismos de atuação, meios de prevenir sua existência ${ }^{(16)}$.

Essa identificação dos riscos pode ocultar ou camuflar as reais origens dos aspectos intervenientes no processo saúde/ doença que em geral situam-se no acesso a bens e serviços, nas desigualdades sociais, nas mazelas produzidas pela organização da sociedade.

Assim, o trabalho educativo necessita avançar em relação a esse enfoque preventivista, pois ele não respalda a mudança nas práticas de saúde. O processo de estranhar, problematizar as "causas" das enfermidades para além dos aspectos individuais parece-nos pertinente para o desenvolvimento da educação em saúde no PACS. 
Outra expressão da noção de prevenção aparece nas falas vinculadas às campanhas contra as doenças como diabetes, hipertensão, hanseníase.

É desenvolver projeto de prevenção de doenças, acho que assim o contexto do trabalho, o objetivo do trabalho é estar trabalhando a prevenção; com isso a gente vai desenvolvendo projetos, assim, de acordo com a necessidade de cada família da comunidade em si (Sabiá).

Fazemos campanhas educativas para hipertensão, diabetes, gravidez... (Beija-flor).

Problematizarmos essa perspectiva com os trabalhadores pode ser um caminho de mudança. A educação permanente em saúde (EPS) ${ }^{(17)}$ pode ser um interessante dispositivo, pois pretende que coletivos de trabalho pensem sobre o que se produz, como, por que, para quem e para que se produz. Ela utiliza metodologias ativas e envolve os trabalhadores, os usuários, os gestores, os docentes e os estudantes para juntos encontrarem caminhos e construírem aprendizados.

\section{Ação educativa e promoção da saúde}

Como aproximação à proposta do PACS de reorientar a atenção, encontramos alguns movimentos que avançam com relação à perspectiva preventivista, chegando ainda mais perto da promoção da saúde ${ }^{(13)}$, que reconhece a multiplicidade de determinantes e a dependência de fatores individuais sociais, ambientais, culturais e políticos, bem como busca superar a dicotomia entre ambiente físico e social.

Embora tenhamos predominância da concepção preventivista e da saúde restrita a aspectos biológicos e individuais, a equipe estudada entende a possibilidade de melhoria da qualidade de vida através da educação em saúde.

Os trabalhadores reconhecem como atividades educativas bem-sucedidas as atividades da caminhada, grupo de fuxico, reunião de quarteirão e ida à biblioteca com as crianças. Nessas ações parecem construir espaços para exercício de autonomia e criação. A caminhada é coordenada pelos próprios moradores, que incentivam uns aos outros para participar do grupo.

A principal delas que a gente faz, o grupo de caminhada, que existe já há mais de um ano, que é três vezes por semana e o grupo já está em torno de umas cinquenta pessoas, dentre elas homens e mulheres; tem o grupo do fuxico, que é o artesanato duas vezes por semana... (Kalopsita).

Foi a da caminhada com as senhoras; a gente está conseguindo educar elas a respeito da alimentação delas, a estarem diminuindo bastante coisa que elas comiam, a estarem se cuidando; tanto é que metade das pessoas da caminhada que entraram com um tanto de medicação hoje em dia algumas nem tomam mais, outras diminuíram (Sabiá).

Outra atividade que se pode apresentar potencializadora da produção de autonomia é a reunião de quarteirão, que é um espaço de conversa em uma residência da microárea, oferecida pelo morador da casa para se discutirem temas livres e de interesse dos vizinhos. Sobre o grupo de fuxico destacamos que a produção é vendida e revertida para ações do próprio grupo, decididas coletivamente, como ações de entretenimento e lazer.

...é muito importante, por exemplo, esse grupo que a gente tem de artesanato; foi uma forma de tirar muitas mulheres da depressão, de conseguirem sair de casa porque muitas delas não saíam; aqui elas veem, se divertem; a caminhada também que a gente faz. sabe, acho que é muito importante para elas tanto na parte assim de ajudar saúde como assim psicologicamente (Canário).

A ida das crianças à biblioteca é uma iniciativa de incentivo à leitura e à melhora do rendimento escolar que surgiu como proposta para retirar as crianças das ruas no período oposto ao horário da escola.

...levar as crianças para biblioteca, essa foi uma que deu certo porque foi muito legal, porque as crianças estão vindo, criança a gente sabe que é difícil prender a atenção delas; então foi bom porque eles estão vindo, a gente aproveita para falar de outros assuntos, não é só lê, sabe, é pra chamar eles (Beija-flor).

Os trabalhadores aproveitam o espaço para abordar outros assuntos que consideram importantes, talvez de um modo mais lúdico, já que é preciso prender a atenção.

Essas ações aproximam-se mais da perspectiva da promoção da saúde ${ }^{(13)}$ do que da prevenção de doenças, visto que investem na participação ativa das pessoas, não estão localizadas em um agravo especifico, mas no bem-estar geral. Elas relacionaram aspectos como convivência, solidariedade e a capacidade de compreender a relação da saúde com os fatores intervenientes no processo saúde/doença, como trabalho, renda, educação, podendo gerar autonomia das pessoas e potencializar a capacidade de organização e luta por direitos.

Certamente isso se apresenta ainda como desafio para as equipes, uma vez que estão mais presentes as ações vinculadas à prevenção, mas o fato de os trabalhadores reconhecerem essas como ações bem-sucedidas assinala movimento que pode consolidar-se em direção à mudança pretendida das práticas, e que por isso necessitam de investimentos e medidas que as fortaleçam.

\section{A ORGANIZAÇÃO DO PROCESSO DE TRABALHO}

Quanto à organização do processo de trabalho, levamos em consideração as ações educativas desenvolvidas e que afastam ou aproximam a equipe de PACS da mudança na prática assistencial.

\section{Apoio da gestão para a educação em saúde}

A gestão da saúde desempenha um papel muito importante para o desenvolvimento das ações educativas, que foi considerado como dificultador para a realização das ações 
de educação em saúde pelos entrevistados. Eles afirmam que nem sempre contam com o necessário apoio para desenvolver suas ações, precisam improvisar e se desestimulam com isso.

...material é muito precário; às vezes a gente quer fazer as coisas, às vezes não pode; maior dificuldade acho que é isso mesmo, financeira (Canário).

Ter materiais em mão, sabe, porque a gente às vezes quer fazer algo e não tem condições, não tem material; é muito difícil o que a gente faz aqui, o possível para dar certo: a caminhada, por exemplo, é difícil a gente não tem professor, a calçada é toda deteriorada, sabe, a gente vai atrás da prefeitura, eles não retornam, caíram várias senhoras; então para se educar é preciso ter também uma estrutura boa, e a gente não tem; aí, a gente deixa a desejar, então isso aí dificulta também, e outros materiais também, na caminhada a gente só pode caminhar, não tem outra alternativa (Gaivota).

O fato de as equipes receberem pouco apoio da gestão local para a realização das ações educativas confirma estudo de $2004^{(11)}$. Embora estejam anunciadas propostas de mudança das práticas assistenciais através de estratégias como o Programa Saúde da Família, com a participação ativa de agentes comunitários, temos uma valorização cotidiana da gestão do sistema e dos trabalhadores ainda distantes da atenção integral à saúde, pois se voltam aos cuidados individuais, apartam as ações de cuidado das ações educativas quando são indissociáveis $^{(6)}$ e valorizam a produtividade e a doença instalada ${ }^{(14-15,18)}$.

\section{A educação em saúde se faz com toda a equipe}

Um aspecto que aproxima os trabalhadores do PACS da sua missão de mudança das práticas vigentes é a constatação de que a educação em saúde necessita de todos os trabalhadores e da prática do trabalho em equipe.

As práticas educativas em saúde significam a construção de ações e relações de diferentes sujeitos sociais, em diferentes ambientes, com diferentes saberes que através de uma prática dialógica e instrumental constroem um saber comum a todos os sujeitos envolvidos na ação ${ }^{(9)}$.

Através da fala a seguir percebemos que há espaço nas reuniões da equipe também para a expressão de sentimentos, o que pode produzir a apropriação e desenvolvimento das tecnologias leves, que são aquelas das relações ${ }^{(9,19)}$, e pode ainda produzir modos mais horizontais de se realizar o trabalho.

Elaborada (se refere a ação educativa) por toda equipe, é a enfermeira que coordena; então, é assim, mediante maiores dificuldades, que as agentes têm, entendeu? Aqui na área ela coordena, assim se programa já para isso. Mas essa reunião, o que vai fazer a equipe que pensa, o sentimento de todos (Kalopsita).

Ações educativas, preventivas, caminhada é uma delas, o curso de gestante, de reeducação alimentar, a enfermeira coordenadora faz as palestras de educação preventiva pros adolescentes na escola, e a gente está participando junto com ela; ação preventiva no sentido da gestante, os riscos que ela tem, se não fizer o pré-natal, a saúde da criança e do adolescente, entendeu?, que o adolescente está mais nas drogas, o uso abusivo de álcool geralmente no adolescente, que mais, do diabético e do hipertenso, também ela faz no sentido de começar mais na educação assim de alimentação do que ele tem (Bem-te-vi).

Nas falas anteriores temos referência à participação do enfermeiro na coordenação de ações, no diagnóstico da necessidade de ações educativas e na coordenação da equipe do PACS. As competências desse profissional para as ações educativas em outra perspectiva que não a normatizadora e de passagem de informações desafiam a formação ${ }^{(20)}$.

Consideramos que a equipe deve planejar as ações educativas a partir das necessidades em saúde, as quais devem ser articuladas com projetos amplos de mudança social, com objetivos a serem atingidos pelos sujeitos envolvidos nesse processo. Nao se pode prescindir de uma análise das condições de trabalho e da organização da rede de atenção no município; assim, questina-se se será possível manter ações individuais e coletivas com uma equipe apenas de PACS composta por uma enfermeira e oito agentes comunitárias para a população em questão. Esses são aspectos a se considerar para a efetiva mudança nas práticas de saúde.

\section{$\mathrm{O}$ ato educativo envolve acolhimento e escuta: tudo que a gente faz é educativo}

Assim como outro estudo(20), os entrevistados reconhecem a relação entre práticas acolhedoras, vinculo e processos educativos. No caso da equipe estudada, pensamos que os trabalhadores vêm percebendo que a saúde precisa atender de modo acolhedor, e isso pode gerar confiança e participação.

...quando a gente faz alguma coisa para as pessoas, acho que tem que ter acolhimento, bom acolhimento, pra poder confiar em você. Se você não trata bem as pessoas, elas não vão querer participar (...) acho que tudo que é bem feito... mais acolhimento, o jeito de você falar com as pessoas... (Canário).

É preciso reconstruir o cuidado comprometendo-se mais com o usuário ${ }^{(19)}$, é preciso ouvir mais, ver mais e tocar mais de um modo diferente. Os trabalhadores reconhecem essa perspectiva:

Olha, eu tenho duas famílias com relação à depressão, que é uma senhora que agradece muito (...) quando a gente começou fazer visita, ela falou que não saía nem de casa, e quando começou a fazer essas coisas, chamar pra participar, hoje ela participa da caminhada, participa aqui também; hoje ela não está aqui, ela está viajando, ela falou que, nossa, ela dá graças a Deus pelo nosso trabalho. Tem uma outra também, estava pior ainda do que essa primeira, precisou da ajuda da psicóloga, que também faz visita com a gente, também fala que a gente tirou ela do fundo do poço. Isso incentiva a gente a continuar (Sabiá). 
O acolhimento e a escuta como um processo norteador do trabalho em saúde e das ações educativas requerem articulações da equipe e de seus saberes. Quando as tecnologias leves $^{(19)}$ comandam o processo de trabalho em saúde, tais como capacidade de vinculo, acolhimento, o desenvolvimento das ações educativas e de cuidado recobram sua indissociabilidade, gerando possibilidades de expressão do cuidado integral.

Outro aspecto que pode direcionar as práticas de saúde para mudanças na atenção aparece na fala de alguns trabalhadores de que toda ação de saúde desenvolvida é educadora.

Praticamente tudo o que a gente faz, né, é educativo; a gente trabalha com prevenção; então passamos informações sobre saúde, sobre prevenção, sobre tudo, tudo que a gente faz é educativo (Sabiá).

Essa perspectiva da não separação entre os diferentes fazeres e o ato educativo abre possibilidades para uma análise sobre o trabalho da equipe, e esse nos parece um promissor caminho para a educação em saúde quando se pretende mudar o modelo assistencial tradicional e produzir sujeitos em ação.

Todo ato em saúde é educador ou deseducador, dependendo de como é executado ${ }^{(6)}$. Quando atendemos de modo inadequado estamos ensinando que a saúde de qualidade não é um direito ou que os direitos podem ser desrespeitados.

\section{CONSIDERAÇÕES FINAIS}

Dentre as ações educativas identificadas e desenvolvidas pela equipe de PACS, encontramos a caminhada, grupo de leitura com crianças, campanhas de hipertensão e diabetes, grupo de fuxico, reunião de quarteirão, dentre outras.

Quanto à concepção pedagógica que alicerça essas atividades, ainda predominam as propostas de educação em saúde sob uma ótica tradicional ou bancária, mas há potencialidades nas ações relatadas pelos trabalhadores que podem trazer impacto na qualidade de vida da população e que caminham no sentido de utilização de metodologias mais ativas e participativas.

Também encontramos concepções preventivistas norteando as ações, culpando e responsabilizando os indivíduos por sua condição de saúde/doença. Apontamos que isso pode afastar a equipe de seu intento de mudanças das práticas, pois não se avança na produção de autonomia, do empoderamento das pessoas e no entendimento da saúde como resultante das condições de vida.

Destacamos ainda os limites nas condições de trabalho e a importância do apoio dos gestores com relação à proposta do PACS promovendo condições materiais para a execução de práticas educativas.

Como potencialidades para a mudança do modelo assistencial, vimos o reconhecimento de que ações educativas devam ser realizadas através do trabalho em equipe, que os atos assistenciais não se separam dos atos educativos e devem incluir acolhimento, escuta ampliada e vínculo.

Reafirmamos que a educação em saúde não é a mera passagem de informações sobre doenças e de recomendações do como se cuidar, mas é encontrar alternativas através da problematização e do diálogo, construindo autonomia.

\section{REFERÊNCIAS}

1. Ministério da Saúde (Brasil). Portaria nº 1886 , de 18 de dezembro de 1997. Institui o Programa de Agentes Comunitários de Saúde e Saúde da Família como importante estratégia para contribuir no aprimoramento e na consolidação do Sistema Único de Saúde [portaria na internet]. Diário Oficial da União $22 \mathrm{dez} 1997$ [acesso em 01 out 2010]. Disponível em: <http://www.saudeprev.com.br/ psf/saopaulo/pdf-geral/Portaria $\% 20$ n $\%$ BA $\% 201886 \% 20$ Programas $\% 20 \mathrm{de} \% 20$ ACS- $\% 20$ PACS $\% 20 \&$ PSF.htm >

2. Ministério da Saúde (Brasil). Portaria n ${ }^{\circ}$.648/GM de 28 de março de 2006. Aprova a Política Nacional de Atenção Básica, estabelecendo a revisão de diretrizes e normas para a organização da Atenção Básica para o Programa Saúde da Família (PSF) e o Programa Agentes Comunitários de Saúde (PACS) [portaria na internet]. Diário Oficial da União 28 de mar 2006 [acesso em 01 out 2010]. Disponível em: <http://www.saude.sc.gov.br/gestores/ Pacto_de_Gestao/portarias/GM-648.html >

3. Morosini MVGC, Fonseca AF, Pereira IB. Educação e saúde na prática do agente comunitário. In: Martins CM, organizadora. Educação e Saúde. Rio de Janeiro: EPSJV/ Fiocruz; 2007. p. 13-34.

4. Trapé CA, Soares CB. Educative practice of community health agents analyzed through the category of praxis. Rev Latino-am Enferm 2007;15(1):142-9.
5. Alves GG. As práticas educativas em saúde e a estratégia saúde da família. Ciênc Saúde Coletiva [periódico na internet]. 2011 jan [acesso em 16 mar 2009]. Disponível em: <http://www.cienciaesaudecoletiva.com.br/artigos/ artigo_int.php?id_artigo $=1151>$.

6. Vasconcelos EM. Educação popular e a atenção à saúde da família. São Paulo: Hucitec; 1999.

7. Minayo MCS. O desafio do conhecimento: metodologia de pesquisa social (qualitativa) em saúde. 5. ed. Rio de Janeiro: Hucited/Abrasco; 1998.

8. IBGE. [homepage internet] Cidades Serrana - SP: Informações estatísticas. [acesso em 27 mar 2009] Disponível em: < http://www.ibge.gov.br/cidadesat/topwindow.htm?1>.

9. Machado MFAS, Vieira NFC. Educação em saúde: o olhar da equipe de saúde da família e a participação do usuário. Rev Latino-am Enferm 2009;17(2):174-9.

10. Bordenave JD. Alguns fatores pedagógicos [Monografia na internet]. Brasília: Ministério da Saúde; 1994. [acesso em 16 ago 2010]. Disponível em: < http://www.opas.org. $\mathrm{br} / \mathrm{rh} /$ publicacoes/textos_apoio/pub04U2T5.pdf $>$.

11. Albuquerque PC, Stotz EN. A educação popular na atenção básica à saúde no município: em busca da integralidade. Interface Botucatu [periódico na internet]. 2004 mar-ago [acesso 11 maio 2010];8(15):259-74. Disponível 
em: < http://www.scielo.br/scielo.php?script=sci_arttext \&pid $=$ S1414-32832004000200006 > .

12. Valla VV. Saúde e Educação. Rio de Janeiro: DP\&A; 2000.

13. Horta NC, Sena RR, Silva MEO, Oliveira SR, Resende VA. A prática das equipes de saúde da família: desafios para a promoção de saúde. Rev Bras Enferm 2009;62(4):524-9.

14. Fleury-Teixeira P, Vaz FAC, Campos FCC, Álvares J, Aguiar RAT, Oliveira VA. Autonomia como categoria central no conceito de promoção de saúde. Ciênc Saúde Coletiva 2008;13(supl.2):2115-22.

15. Costa GD, Cotta RMM, Ferreira MLSM, Reis JR, Franceschini SCC. Saúde da família: desafios no processo de reorientação do modelo assistencial. Rev Bras Enferm 2009;62(1):113-8.

16. Arouca S. O dilema preventivista: contribuição para a compreensão e crítica da Medicina Preventiva. Rio de Janeiro: Fiocruz; 2003.

17. Burg Ceccim R, Feuerwerker LCM. O quadrilátero da formação para a área da saúde: ensino, gestão, atenção e controle social. Physis 2004;14(1):41-65.

18. Camelo SHH, Angerami ELS. Estratégias de gerenciamento de riscos psicossociais no trabalho das equipes de saúde da família. Rev Eletrônica Enferm [periódico na internet]. 2008 [acesso em 11 maio 2010];10(4):915-23. Disponível em: < http://www.fen.ufg.br/revista/v10/n4/v10n4a04.htm > .

19. Merhy EE. Saúde: a cartografia do trabalho vivo. São Paulo: Hucitec; 2002.

20. Leonello VM, Oliveira MAC. Competências para ação educativa da enfermeira. Rev Latino-am Enferm 2008;16(2):177-83. 